McIntyre, H. D., and McIntyre, A. P. (1942). Amer. F. Psychiat., 98, 720.

Malherbe (1833). Sur les Tumeurs qui se développent dans l'Intérieur du Crâne. Thèse de Paris

Morse, M. E. (1920). Arch. Neurol. Psychiat. (Chic.), 3, 417.

Olivecrona, H. (1934). Die parasagittalen Meningeome. Leipzig.

Patton, R. B., and Sheppard, J. A. (1956). Amer. F. Psychiat., 113, 319.

Redlich, E. (1912). Die Psychosen bei Gehirnerkrankungen. Leipzig.

Russell, D. S., and Rubinstein, L. J. (1959). Pathology of Tumours of the Nerious System. London.

Selecki, B. R. (1964). Med. F. Aust., 2, 954.
Smith, S., and Hemphill, R. E. (1956). Y. Neurol. Neworosurg. Psychion., $19,42$.

Soniat, T. L. L. (1951). Amer. Y. Psychiat., 108, 19.

Waggoner, R. W., and Bagchi, B. K. (1953-4). Amer. F. Psychiat., 110, 904. Wilson, S. A. K. (1940). Neurology, edited by A. N. Bruce, vol. 2.

Wood, M. W., White, R. J., and Kernohan, J. W. (1957). 9. Neuroparh. exp Neurol., 16, 337.

Zülch, K. J. (1951). Die Hirngeschwülste in biologischer wand morphologischer Darstellung. Leipzig.

\title{
The Elderly in the Wrong Unit
}

\author{
ALEX G. MEZEY,* M.D., M.R.C.P.ED., D.P.M. ; H. M. HODKINSON, $†$ M.A., B.M., M.R.C.P. \\ GRAHAM J. EVANS, $\ddagger$ M.B., D.P.M.
}

Brit. med.F., 1968, 3, 16-18

\begin{abstract}
Cummary : Patients over 65 admitted from an area of $S$ North London forming the overlapping part of the catchment areas of a geriatric unit and a psychiatric unit were studied, with particular reference to misplacement in the inappropriate hospitals service and its consequences.
\end{abstract}

The incidence of misplacement found was much lower than previously reported. In the geriatric unit $2.2 \%$ of admissions were definitely and $6.0 \%$ were probably misplaced. In the psychiatric unit $6.2 \%$ were definitely and a further $8.4 \%$ were probably misplaced. Misplacement did not materially affect the outcome. The striking differences that were found between the patterns of death and discharge in the geriatric and psychiatric units were determined principally by the type of illness leading to admission.

The frequent coexistence of mental and physical disorders in the elderly patient, which this study confirms, indicates the need for further development of effective liaison at a local level between the geriatric, psychiatric, and social services.

\section{Introduction}

Recent thinking on geriatric services has favoured the establishment of assessment units with subsequent disposal of patients according to their needs. Much of this thought has been influenced by the findings of Kidd (1962a) in his study of old people in Belfast. He found that a large number of geriatric patients suffered both mental and physical illness, that many were admitted to the inappropriate hospital, and suggested that the prognoses of these patients were worse as a result (Kidd, 1962b).

The present paper describes part of a study designed to explore the need for such an assessment unit. It was carried out in the densely populated working-class boroughs of Tottenham and Edmonton (total population 204,205, with 25,376 aged 65 years and over at the 1961 Census) in North London. This is the only overlapping part of two much more extensive and independently run geriatric and psychiatric services; it is divided between two different local authorities. The geriatric

\footnotetext{
* Consultant Psychiatrist.

t Consultant Geriatrician.

$¥$ Research Assistant.

North Middlesex Hospital, London N.18.
}

service, to be referred to subsequently as the geriatric unit, has 181 admission beds (at the North Middlesex Hospital, Edmonton, and at St. Ann's General Hospital, Tottenham), with another 79 beds in long-stay annexes. The psychiatric service, which will be called the psychiatric unit, has 77 geriatric admission beds at Claybury Hospital, Essex, with a small number of additional beds in general psychiatric admission wards at the North Middlesex Hospital and at Claybury Hospital. There are also a large number of long-stay beds at Claybury Hospital.

\section{Methods}

Patients aged 65 and over from Tottenham or Edmonton who were admitted to the geriatric or psychiatric unit in the year from 8 May 1965 to 7 May 1966 were the subjects of the study. All admissions to the psychiatric unit were included, but a one-in-four random sample of admissions to the geriatric unit was taken so as to have roughly equal numbers. Within the first few days of admission the patients received a full psychiatric and medical examination, based on a standard form designed after a pilot study. Their behaviour was assessed separately by one of us (G. J. E.) and by the nursing staff, and recorded on the Crichton Royal Behaviour Rating Scale (Robinson, 1959). The Inglis Paired Associate Test (Inglis, 1959) was used in some cases. When necessary, patients' relatives were interviewed and their homes visited.

The course of each patient's illness was followed, and on discharge from hospital their behaviour was again assessed on the same behaviour rating scale. Six months after admission the outcome of each patient was recorded, and those who were alive were interviewed and their condition was assessed on a standard form. The results were transferred to punched cards for analysis.

The patients were classified in four different groups according to Kidd's terminology: (1) mental, (2) mental-physical, (3) physical-mental, and (4) physical. Patients in group 1 were diagnosed as suffering from psychiatric disorders only, and patients in group 4 from somatic disorders only. Patients in groups 2 and 3 were suffering from both psychiatric and somatic disorders, the first-mentioned being the main condition leading to hospital admission. Therefore in the geriatric unit groups 1 and 2 were misplaced; and in the psychiatric unit groups 3 and 4 were misplaced. One of us (G.J.E.) examined and assigned individual patients to one of the four groups, but difficult or borderline cases were placed after discussion 
between all three of us. So far as was possible doctors who were responsible for the clinical management of the patients were unaware of which patients were being investigated.

\section{Results}

A total of 233 admissions to the geriatric unit and 130 admissions to the psychiatric unit were examined. Tables I and II show the distribution of the four diagnostic groups

TABlE I.-Outcome Six Months after Admission to one of the Hospital Services for the Elderly with a Predominantly Psychiatric Condition

\begin{tabular}{|c|c|c|c|c|c|}
\hline & & \multirow{2}{*}{\multicolumn{2}{|c|}{$\frac{\text { Group } 1 \text { (Mental) }}{\text { Admitting Unit }}$}} & \multirow{2}{*}{\multicolumn{2}{|c|}{$\frac{\text { Group } 2 \text { (Mental-Physical) }}{\text { Admitting Unit }}$}} \\
\hline & & & & & \\
\hline & & Geriatric & Psychiatric & Geriatric & Psychiatric \\
\hline All patients & .. & 5 & 62 & 14 & 49 \\
\hline $\begin{array}{l}\text { Died .. } \\
\text { Still in hospital } \\
\text { Discharged }\end{array}$ & $\ddot{0}$ & $\begin{array}{l}1 \\
0 \\
4\end{array}$ & $\begin{array}{l}11 \\
13 \\
38\end{array}$ & $\begin{array}{l}4 \\
2 \\
8\end{array}$ & $\begin{array}{l}10 \\
12 \\
27\end{array}$ \\
\hline $\begin{array}{l}\text { All patients survi } \\
\text { Alive outside hos? }\end{array}$ & $\ddot{n}$ & $\begin{array}{l}4 \\
4\end{array}$ & $\begin{array}{l}50 \\
37\end{array}$ & $\begin{array}{l}7 \\
5\end{array}$ & $\begin{array}{l}37 \\
25\end{array}$ \\
\hline
\end{tabular}

TABLE II.-Outcoms Six Months after Admission to one of the Hospital Services for the Elderly with a Predominantly Physical Condition

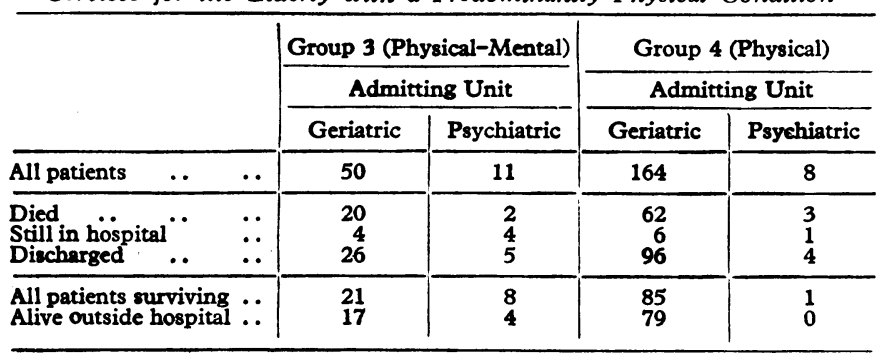

between the two units, and the outcome six months after admission. Among those admitted to the geriatric unit 214 $(91.8 \%)$ were correctly placed according to the criteria used ; of the remainder $5(2.2 \%)$ were definitely misplaced, as they belonged to group 1 , and the $14(6.0 \%)$ in group 2 were probably misplaced. Corresponding figures for the psychiatric unit were $111(85.4 \%)$ correctly placed, $8(6.2 \%)$ in group 4 definitely misplaced, and $11(8.4 \%)$ in group 3 probably misplaced. Misplacement of patients in proportion to the total number of admissions is therefore greater in the psychiatric than in the geriatric unit, but, since the geriatric figures are taken from a one-in-four sample, in total numbers the misplacement of patients into geriatric beds is considerably greater than those into psychiatric beds.

Of the 19 patients misplaced in the geriatric unit five were holiday admissions-that is, booked 14-day admissions to allow relatives to take their annual holiday. Of a total of 11 holiday admissions in the sample there were three patients with severe mental as well as physical disability in addition to the five cases classified as "mental." This suggests that there is a need for a similar holiday admission service to be organized by the psychiatric unit.

TABLB III.-Survival at Six Months after Admission, Expressed as Percentage of Patients Admitted

\begin{tabular}{|c|c|c|c|c|}
\hline \multicolumn{2}{|l|}{ Group } & $\begin{array}{c}\text { Geriatric } \\
\text { Unit }\end{array}$ & $\begin{array}{l}\text { Prychiatric } \\
\text { Unit }\end{array}$ & $\begin{array}{c}\text { Total } \\
\text { Survival }\end{array}$ \\
\hline $\begin{array}{l}\text { 1. Mental } \\
\text { 2. Mental-Physical } \\
\text { 3. Physical-Mental } \\
\text { 4. Physical } \quad \text {.. }\end{array}$ & $\ddot{0}$ & $\begin{array}{l}80 \cdot 0 \\
50 \cdot 0 \\
42 \cdot 0 \\
51 \cdot 8\end{array}$ & $\begin{array}{l}80 \cdot 7 \\
75 \cdot 5 \\
72 \cdot 7 \\
12 \cdot 5\end{array}$ & $\begin{array}{l}80 \cdot 6 \\
69 \cdot 8 \\
47 \cdot 5 \\
50 \cdot 0\end{array}$ \\
\hline All groups & .. & $50 \cdot 2$ & $73 \cdot 8$ & $62 \cdot 0$ \\
\hline
\end{tabular}

Survival at Six Months (Table III).-There were marked differences between the four groups. In group 162 patients were correctly placed in the psychiatric unit and $50(80.7 \%$ ) survived ; the other five patients were misplaced in the geriatric unit and four (80\%) survived. In group 2, of 49 correctly placed patients $37(75.5 \%)$ were alive six months later ; $7(50 \%)$ survived of the 14 patients of this group admitted to the geriatric unit. In group 3 there were 50 patients correctly placed in the geriatric unit, 21 (42\%) surviving, while $8(72.7 \%)$ out of the 11 patients admitted to the psychiatric unit did so. In group 4, of 164 patients correctly placed in the geriatric unit $85(51.8 \%)$ survived, compared with one survivor $(12.5 \%)$ among the eight patients misplaced in the psychiatric unit.

Time of Death.-As is shown in the Chart, the initial death rate in the geriatric unit is high, but it falls after the first two weeks to a much lower and fairly steady rate. In contrast, there is no early peak for deaths in the psychiatric unit.

Time of Discharge.-The Chart again shows the differences found between the two units. There is an earlier peak (one to four weeks) for the geriatric unit compared with a peak between the fourth and eighth weeks for the psychiatric unit. In both units the discharge peak for patients with both physical and mental disabilities was about one week later than for patients with mental or physical disability alone.

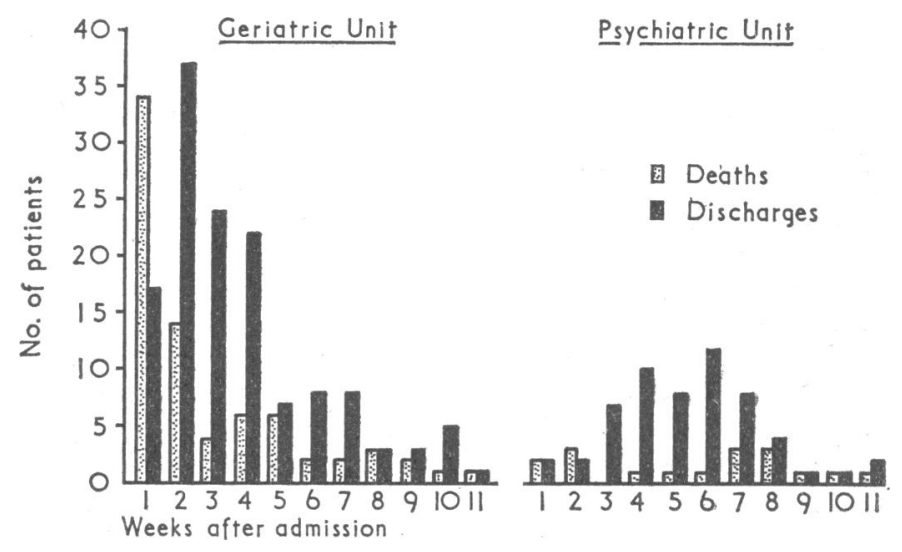

Time of death and discharge in the two hospital services for the elderly.

Table III summarizes the survival findings six months after admission. Statistical analysis shows a highly significant difference between the overall survival figures for the two units $\left(\chi^{2}=17.9 ; \mathrm{P}<0.001\right)$. In contrast, the survival rates for misplaced patients $(57.9 \%)$ and correctly placed patients $(59.4 \%)$ are not significantly different. In one subgroup the observed survival rate differs significantly from others in that unit. This is the group of eight misplaced "physical" patients admitted to the psychiatric unit, of whom only one survived $\left(\chi^{2}=16.654 ; \mathrm{P}<0.001\right)$. The diagnoses were $4(50 \%)$ with malignant disease (carcinoma of the bronchus with haemorrhage into a cerebral secondary, pneumonia due to carcinoma of bronchus, carcinoma of the colon with intestinal obstruction, carcinoma of the rectum with haemorrhagic anaemia), $2(25 \%)$ with cerebrovascular accidents ( 1 cerebral embolism, 1 subarachnoid haemorrhage), 1 congestive cardiac failure, and 1 chorea. In contrast, of the "physical" group admitted to the geriatric unit $11.7 \%$ had malignant disease, $14.7 \%$ cerebrovascular accidents, and $22.7 \%$ heart disease. It can be seen that the two subgroups were different diagnostically, and that the first six cases had a very bad prognosis irrespective of the place of admission, and in fact all died. The patient with congestive cardiac failure survived. The patient with chorea died suddenly from myocardial infarction after discharge from hospital.

Patients with both physical and mental disorders admitted to the two units differed in some important respects. The physical disorders of patients admittted to the geriatric unit 
were generally more severe than of those admitted to the psychiatric unit. Dementia in patients admitted to thé psychiatric unit was usually more advanced, so that mental deterioration occurred at an earlier stage of physical illness. These differences probably explain the poorer survival rates for such patients in the geriatric unit, irrespective of correct placement or misplacement. That physical disease carries a worse prognosis than mental is confirmed by the progressive fall in overall survival rates as one passes from group 1 to group 4 .

\section{Discussion}

Our findings differ from those of Kidd (1962b). He reported that in Belfast, of geriatric admissions $13 \%$ were definitely misplaced and a further $11 \%$ were probably misplaced in the psychiatric hospital, while in the geriatric hospital the corresponding figures for misplacement were 20 and $14 \%$. In the present study the relevant figures in the psychiatric unit were $6.2 \%$ definitely and $8.4 \%$ probably misplaced ; $2.2 \%$ definitely and $6.0 \%$ probably misplaced in the geriatric unit. While misplacement is undesirable by definition-that is, another service would be more appropriate-it may not always be possible to avoid it before admission and investigation in hospital, particularly in a population in which concomitant physical and psychiatric symptoms are very common. It may be considered that the number we found misplaced in this way in the geriatric unit was not unduly large, and probably not far in excess of admissions to medical wards of patients requiring ultimately surgical rather than medical measures. What invalidates this analogy is the frequent separation, geographical and attitudinal, between geriatric and psychiatric branches of the hospital service.

We are not able to confirm Kidd's findings that misplacement had an adverse effect on survival. Only in the small group of physical patients admitted to the psychiatric unit is there any evidence for this. The marked differences in diagnoses and prognoses between this group and the physical patients admitted to the geriatric unit account for the high mortality observed.

There is a highly significant difference between survival rates for all patients admitted to the two units. Mortality is much higher in the geriatric unit, and there is an early peak of deaths (within two weeks of admission) not found in the case of the psychiatric unit. These findings are related to differences in the type of patient admitted, and perhaps also to the virtual absence of a waiting-list for the geriatric unit, facilitating the admission of critically ill patents.

We can only speculate about the reasons for the differences between our findings and those of Kidd. His lower age limit was 60 , while ours was 65 , and our study covered a whole year. A major difference is that he saw cases three weeks after admission. As can readily be seen from the Chart, this practice would have excluded a large number of the patients we studied, particularly in the case of the geriatric unit.

Physical and mental disorder are often present together in the elderly patient admitted to hospital. In the geriatric unit psychiatric disorders of varying severity are present in $30.0 \%$ of patients (groups 1, 2, and 3). This compares with $63 \%$ in Belfast (Kidd, 1962b) and over $58 \%$ in Newcastle (Kay, Beamish, and Roth, 1962). In the psychiatric unit we found that $52.3 \%$ of patients (groups 2,3 , and 4 ) were suffering from a physical illness or disability. The corresponding figures were $47 \%$ in Belfast (Kidd, 1962b), $28 \%$ in Newcastle (Kay et al., 1962), and $33 \%$ in Brighton (Herbert and Jacobson, 1966). The high prevalence of coexisting physical and mental disorders is therefore confirmed. A corollary of this observation is that, whichever the admitting hospital service, the diagnosis and treatment of the elderly patient required both medical and psychiatric skills.

The case for comprehensive psychogeriatric assessment units has been cogently argued by Kay, Roth, and Hall (1966). It would appear that if the sole purpose of psychogeriatric assessment units was to prevent misplacement by sifting through all admissions then little would be achieved by setting one up in this area. The fact that comparatively few misplacements have been found in this study, and that misplacement did not materially affect the outcome, indicates that all patients need not go through a special assessment unit. The most important function of these units would be to promote the cohesion of the relevant components of the services for the elderly sick. It would, in addition, serve as a centre to give joint psychiatric and medical training to nurses and doctors working in all branches of the geriatric services. Much thought should be given to the type of patients admitted to such a unit, and a further paper will explore this subject.

However, close liaison between the two branches of the hospital service and of both with the local authority services is a more urgent need-and an objective more readily attainable-than the establishment of special units in large numbers. Indeed, co-operation is required not only in the assessment phase but throughout the illness in both hospital services, as the considerable overlap of physical and mental conditions often makes total separation impossible or an arbitrary decision. Thus one of the main sources of misplacement in Belfast (Kidd, 1962b) was the transfer of elderly patients to the psychiatric hospital after initial admission into an acute medical ward. When geriatrics and psychiatry are both centred on the same general hospital the developing co-operation tends to resolve difficulties experienced in the past. To promote this it may be necessary to allocate sessional time for geriatricians and psychiatrists to advise on the care of patients admitted to the parallel unit. This need is even more urgent when geriatric and psychiatric beds are separated from each other in specialized hospitals. In view of the relevance of both disciplines to the diagnosis and treatment of medical conditions of old age, the creation of a joint training programme-perhaps at senior-registrar level-seems desirable.

We are grateful to the North-east Metropolitan Regional Hospital Board for a financial grant. We also wish to thank our colleagues at the North Middlesex Hospital and Claybury Hospital for access to patients under their care.

\section{REFERENCES}

Herbert, E., and Jacobson, S. (1966). Brit. F. Psychiat., 112, 589.

Herbert, E., and Jacobson, S. (1966), 40 .

Kay, D. W. K., Beamish, P., and Roth, M. (1962). The Sociological Review, edited by P. Haimos, Monogr. No. 5, p. 173. Keele.

Kay, D. W. K., Roth, M., and Hall, M. R. P. (1966). Brit. med. Y., 2, 967.

Kidd, C. B. (1962a). Brit. med. F., 2, 1491.

Robinson, R. A. (1959). A Behaviour Rating Scale for Geriatric Mental Patients. Crichton Royal Hospital, Dumfries. 